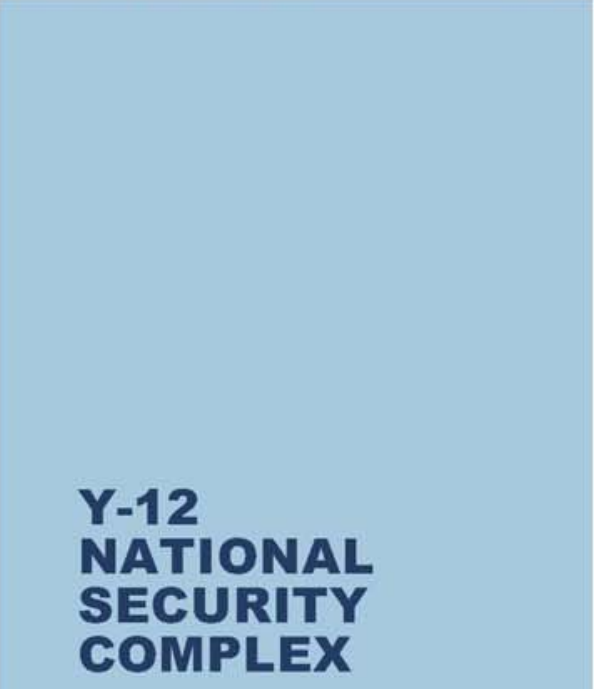

\title{
Elastic Properties and Internal Friction of Two Magnesium Alloys at Elevated Temperatures
}

\author{
M. Freels, P.K. Liaw \\ University of Tennessee, Knoxville, TN 37996 \\ E. Garlea, J. S. Morrell \\ Y-12 National Security Complex \\ M. Radiovic \\ Texas A\&M University, College Station, TX 77843
}

June 2011 


\section{DISCLAIMER}

This report was prepared as an account of work sponsored by an agency of the United States Government. Neither the United States Government nor any agency thereof, nor any of their employees, makes any warranty, express or implied, or assumes any legal liability or responsibility for the accuracy, completeness, or usefulness of any information, apparatus, product, or process disclosed, or represents that its use would not infringe privately owned rights. Reference herein to any specific commercial product, process, or service by trade name, trademark, manufacturer, or otherwise, does not necessarily constitute or imply its endorsement, recommendation, or favoring by the United States Government or any agency thereof. The views and opinions of authors expressed herein do not necessarily state or reflect those of the United States Government or any agency thereof.

\section{COPYRIGHT NOTICE}

"The submitted manuscript has been authored by a contractor of the U.S. Government under contract DE-AC05-00OR22800.

Accordingly, the U.S. Government retains a paid-up, nonexclusive, irrevocable, worldwide license to publish or reproduce the published form of this contribution, prepare derivative works, distribute copies to the public, and perform publicly and display publicly, or allow others to do so, for U.S. Government purposes.” 


\begin{abstract}
The elastic properties and internal friction of two magnesium alloys were studied from $25^{\circ} \mathrm{C}$ to $450^{\circ} \mathrm{C}$ using Resonant Ultrasound Spectroscopy (RUS). The Young's moduli decrease with increasing temperature. At $200^{\circ} \mathrm{C}$, a change in the temperature dependence of the elastic constants is observed. The internal friction increases significantly with increasing temperature above $200^{\circ} \mathrm{C}$. The observed changes in the temperature dependence of the elastic constants and the internal friction are the result of anelastic relaxation by grain boundary sliding at elevated temperatures.
\end{abstract}

Keywords: magnesium alloys; elastic behavior; high temperature deformation; resonant ultrasound spectroscopy 
Elastic properties govern the behavior of a materials subjected to stress over a region of strain where the material behaves elastically. The elastic properties, including the Young's modulus (E), shear modulus (G), bulk modulus (B), and Poisson's ratio (v), are of significant interest to many design and engineering applications. The choice of the most appropriate material for a particular application at elevated temperatures therefore requires knowledge of its elastic properties as a function of temperature. In addition, mechanical vibration can cause significant damage in the automotive, aerospace, and architectural industries and thus, the ability of a material to dissipate elastic strain energy in materials, known as damping or internal friction, is also important property. Internal friction can be the result of a wide range of physical mechanisms, and depends on the material, temperature, and frequency of the loading [3]. When utilized effectively in engineering applications, the damping capacity of a material can remove undesirable noise and vibration as heat to the surroundings [3].

The elastic properties of materials can be determined by static or dynamic methods [1]. Resonant Ultrasound Spectroscopy (RUS), used in this study, is a unique and sophisticated non-destructive dynamic technique for determining the complete elastic tensor of a solid by measuring the resonant spectrum of mechanical resonance for a sample of known geometry, dimensions, and mass [3]. In addition, RUS allows determination of internal friction, or damping, at different frequencies and temperatures.

Polycrystalline pure magnesium (Mg) exhibits excellent high damping properties [4]. However, the poor mechanical properties limit the applications of pure Mg. Although alloying can improve the mechanical properties of Mg, the damping properties are reduced with additions of alloying elements [5]. Therefore, it becomes necessary to study and develop Mg-alloys with simultaneous high damping capacity and improved mechanical properties. Moreover, studies involving the high temperature dynamic elastic properties of Mg alloys are limited [6].

In this study, the elastic properties and internal friction of two magnesium alloys were studied at elevated temperatures using RUS. The effect of alloy composition and grain size was investigated. The wrought magnesium alloys AZ31 and ZK60 were employed. Table 1 gives the nominal chemical compositions of these two alloys. The ZK60 alloy is a commercial extruded plate with a $\mathrm{T} 5$ temper, i.e. solution-treated at $535^{\circ} \mathrm{C}$ for two hours, quenched in hot water, and aged at $185^{\circ} \mathrm{C}$ for 24 hours [7]. The AZ31 alloy is a commercial rolled plate with a H24 temper, i.e. strain hardened and partially annealed [8].

The ZK60 alloy has two well-defined texture components [7], one with the basal planes parallel to the Extruded Direction (ED), and the other with the basal poles parallel to the Transverse Direction (TD). There is a greater angular spread in the pole density from the Normal Direction (ND), toward TD than toward ED. The ZK60 material has two grainsize components: larger grains of 50 - $100 \mu \mathrm{m}$, and smaller grains of less than $10-15 \mu \mathrm{m}$ [7]. However, the AZ31 alloy exhibits radial symmetry [8], namely, the basal poles are concentrated at the center of the (00.2) pole figure and are preferentially oriented perpendicular to the Rolling Direction (RD). The intensity in the (10.0) pole figure is 
essentially uniform around the perimeter. The AZ31 material has an average grain size of $50 \mu \mathrm{m}[8]$.

To measure the Coefficients of Thermal Expansion (CTE), a Thermo-Mechanical Analyzer (TMA) Q400 EM was utilized. The samples were cylindrical in shape, with the height and diameter being approximately $7.6 \mathrm{~mm}$ and $6.5 \mathrm{~mm}$, respectively. The RD (for AZ31) and the ED (for ZK60) were parallel to the height dimension. Nitrogen gas was flowed at a rate of $100 \mathrm{ml} / \mathrm{min}$ in the specimen chamber during the test. Utilizing the expansion probe, measurements were taken from room temperature $\left(25^{\circ} \mathrm{C}\right)$ to $450^{\circ} \mathrm{C}$ at $2^{\circ} \mathrm{C} / \mathrm{min}$ and an applied load of $1.98 \mathrm{~N}$. The preload force employed during the setup was $0.2 \mathrm{~N}$. During RUS analysis, the measured CTEs were employed to account for changes in the sample dimensions as the temperature increased. Those results were used to calculate dimensional changes of the samples with temperature that was needed for accurate spectra fitting in RUS.

Thin disk type samples were machined from the as-received AZ31 and ZK60 plates. The initial sample diameter and thickness were $24 \mathrm{~mm}$ and $2 \mathrm{~mm}$, respectively. The RD (for AZ31) and the ED (for ZK60) were parallel to thickness direction. Assuming cubic symmetry (with three independent elastic constants, namely $\mathrm{C}_{11}, \mathrm{C}_{12}$, and $\mathrm{C}_{44}$ ), the first 40 resonant peaks were fitted for every spectrum. An approximate spectrum is calculated from a set of "guessed" elastic constants $\mathrm{C}_{11}, \mathrm{C}_{12}$, and $\mathrm{C}_{44}$ for cubic solids, and the known sample dimensions and density. The root-mean-square (RMS) error between the measured and calculated resonant peaks is minimized by a multidimensional algorithm (Quasar International, Albuquerque, NM). This enables the determination of the elastic constants from a single frequency scan. For cubic symmetry, E can be calculated for different directions from known elastic constants using the following

$E^{-1}=S_{11}-2\left(S_{11}-S_{12}-\frac{1}{2} S_{44}\right)\left(\sin ^{2} \phi \cos ^{2} \phi+\frac{1}{4} \sin ^{4} \phi \sin ^{2} 2 \theta\right)$

where $\phi$ and $\theta$ are polar angles relative to crystallographic directions. The stiffness components $\left(\mathrm{S}_{11}, \mathrm{~S}_{12}\right.$ and $\left.\mathrm{S}_{44}\right)$ are related to the compliances by

$C_{11}=\frac{S_{11}+S_{12}}{\left(S_{11}-S_{12}\right)\left(S_{11}+2 S_{12}\right)}$

$C_{12}=\frac{-S_{12}}{\left(S_{11}-S_{12}\right)\left(S_{11}+2 S_{12}\right)}$

$C_{44}=\frac{1}{S_{44}}$

Measurements were performed for each sample in the 0 - $250 \mathrm{kHz}$ frequency range from $25^{\circ} \mathrm{C}$ up to $450^{\circ} \mathrm{C}$. To reduce temperature gradients at elevated temperatures, the sample was held for five minutes before measurements were taken. In addition, the high temperature experiments were carried out in vacuum to avoid oxidation. The hightemperature RUS system has been proven as an accurate and practical technique to 
determine elastic moduli of different metallic and ceramic materials in $25-1300^{\circ} \mathrm{C}$ temperature range [1, 9-10].

In addition to the elastic moduli, the internal friction, $\mathrm{Q}^{-1}$, was determined from the RUS spectra according to the following equation [2]:

$Q_{k}^{-1}=\frac{\Delta \omega_{k}}{\omega_{k_{0}}}$

where $\omega_{k_{0}}$ is the frequency associated with the kth eigenmode, and $\Delta \omega_{k}$ is the full width at half maximum (FWHM) of that mode.

The dimensional change as a function of temperature is shown in Fig. 1 in the ED for ZK60 and the RD for AZ31. Linear behavior is observed from $25^{\circ} \mathrm{C}$ to $450^{\circ} \mathrm{C}$ for the AZ31 alloy, with a CTE value of $24.41 \mu \mathrm{m} / \mathrm{m}^{\circ} \mathrm{C}$. From $25^{\circ} \mathrm{C}$ to $275^{\circ} \mathrm{C}$, the ZK60 alloy displays linear behavior, with a CTE of $23.31 \mu \mathrm{m} /\left(\mathrm{m}^{\circ} \mathrm{C}\right)$. A gradual decrease in slope occurs at $275^{\circ} \mathrm{C}$, followed by an increase in slope. Linear behavior is again observed between $300^{\circ} \mathrm{C}$ to $450^{\circ} \mathrm{C}$, with a CTE of $25.45 \mu \mathrm{m} /\left(\mathrm{m}^{\circ} \mathrm{C}\right)$. The small deviation from linearity could be attributed to some type of recrystallization process. In fact, static recrystallization in a ZK60 alloy at $300^{\circ} \mathrm{C}$ has been previously observed [11]. The previous thermo-mechanical analysis results showed that AZ31 and ZK60 alloys are reasonably isotropic in their thermal expansion behavior [12].

Typical RUS spectra obtained for ZK60 at $25^{\circ} \mathrm{C}, 250^{\circ} \mathrm{C}$, and $450^{\circ} \mathrm{C}$ is shown in Figs. 2a-2c, respectively. The RMS error between measured and calculated resonant frequencies was always less than $0.6 \%$ at all temperatures. It can be seen that the resonance peaks shift towards lower frequencies and broaden with temperature. The peak shift is a result of the decrease of elastic constants with temperature, while the peak broadening is a result of an increase in internal friction (mechanical damping) with increasing temperature. The results for AZ31, although not shown here, were similar to the ones shown in Fig. 2.

The temperature dependence of $\mathrm{E}$ in ED for ZK60 and RD for AZ31 and the compliances $\mathrm{C}_{11}, \mathrm{C}_{12}$, and $\mathrm{C}_{44}$, is shown in Figure 3 . For both alloys, $\mathrm{C}_{11}, \mathrm{C}_{12}$, and $\mathrm{C}_{44}$ decrease with increasing temperature. Moreover, from $25^{\circ} \mathrm{C}$ to $200^{\circ} \mathrm{C}$, the elastic properties of both alloys display linear temperature dependence. The temperature dependences (slopes) of $\mathrm{E}(\mathrm{dE} / \mathrm{dT}), \mathrm{C}_{11}\left(\mathrm{dC}_{11} / \mathrm{dT}\right), \mathrm{C}_{12}\left(\mathrm{dC}_{12} / \mathrm{dT}\right)$ and $\mathrm{C}_{44}\left(\mathrm{dC}_{44} / \mathrm{dT}\right)$ (assuming linear dependence with temperature) from $25^{\circ} \mathrm{C}$ to $200^{\circ} \mathrm{C}$ are given in Table 2 . The temperature dependence for $\mathrm{E}$ is well described assuming linearity. The $\mathrm{dE} / \mathrm{dT}$ for AZ31 from room temperature to $200^{\circ} \mathrm{C}$ in the present study is in good agreement with the results from Watanabe et al. [6]. Moreover, the $\mathrm{dE} / \mathrm{dT}$ from room temperature to $200^{\circ} \mathrm{C}$ for both AZ31 and ZK60 were close to that previously published for pure magnesium [13].

The slopes of elastic constants (assuming linear dependence with temperature) from $200^{\circ} \mathrm{C}$ to $450^{\circ} \mathrm{C}$ are given in Table 3 . Above $200^{\circ} \mathrm{C}$, the temperature dependences of the elastic properties for both alloys change when compared to that below $200^{\circ} \mathrm{C}$. For 
example, $\mathrm{dE} / \mathrm{dT}$ for both alloys increases when compared to the temperature dependence below $200^{\circ} \mathrm{C}$. This is particularly the case for the ZK60 alloy. The difference in $\mathrm{dE} / \mathrm{dT}$ above and below $200^{\circ} \mathrm{C}$ is slightly larger for the ZK60 alloy when compared to that for the AZ31 alloy. Moreover, the goodness of fitting $\left(\mathrm{R}^{2}\right)$ above $200^{\circ} \mathrm{C}$ is generally lower when compared to that below $200^{\circ} \mathrm{C}$, suggesting a larger deviation from linearity in the temperature dependences above $200^{\circ} \mathrm{C}$.

The temperature dependence of the internal friction for AZ31 and ZK60 is shown in Figure 4 . The frequencies of the peaks at room temperature used in this study were 25.26 $\mathrm{kHz}$ and $27.40 \mathrm{kHz}$ for ZK60 and AZ31, respectively. The same peak for each material was used for all measurements. From $25^{\circ} \mathrm{C}$ up to around $200^{\circ} \mathrm{C}$, ZK60 and AZ31 alloys display similar behavior. Their damping capacities only slightly increase with increasing temperature. The damping capacity of ZK60 is slightly higher than that of AZ31 below $200^{\circ} \mathrm{C}$. However, above $200^{\circ} \mathrm{C}$ for AZ31 and above $300^{\circ} \mathrm{C}$ for ZK60, the damping capacity of both alloys increases significantly with temperature.

If a material does not go through any phase transformation during heating, the elastic moduli usually decrease almost linearly with temperature, and can be described by the following approximate equation [14]:

$$
\frac{E}{E_{0}}=\left[1-a\left(\frac{T}{T_{m}}\right)\right]
$$

where $E$ is the modulus at temperature $T, T_{m}$ is the melting temperature, and $E_{0}$ the modulus at $0 \mathrm{~K}$. The proportionality constant $a$ is around 0.5 for most crystalline materials. However, elastic properties at elevated temperatures can deviate from linearity because of the different anelastic effects, including grain boundary sliding [15]. This can result in anelastic relaxation and consequently a decrease in the observed elastic constants when compared to unrelaxed elastic constants, or those determined in the absence of grain boundary sliding [16].

Both alloys examined here shows non-linear decrease in elastic constants with temperature, above approximately $200^{\circ} \mathrm{C}$. The larger deviation from linearity observed in change of elastic constants vs. temperature plots for the ZK60 alloy when compared to that of the AZ31 alloy suggests that differences in grain sizes between two alloys, and possibly observed recrystallization in ZK60, play an important role. It is well known that grain boundary sliding increases with decreasing grain size [17]. The larger grains in the AZ31 alloy should produce less viscous flow and grain boundary sliding in this alloy when compared to that of the ZK60, resulting in smaller temperature dependence changes and deviations from linearity in the elastic properties at elevated temperatures. In addition, recrystallization of ZK60 results in further reduction of the grain sizes, which in turn leads to the more intensive grain boundary sliding and stronger anelastic relaxation.

Another indirect evidence of the effect that anelastic relaxation due to grain boundary sliding above $200^{\circ} \mathrm{C}$ have on elastic moduli is evident in Fig. 4. Internal friction is 
generally defined as the dissipation of elastic mechanical energy in the material [3]. If grain boundary sliding is activated as a dissipation mechanism at a certain temperature, the damping capacity increases with temperature because the sliding of the grain boundaries converts the mechanical energy into thermal energy as a result of internal friction at the grain boundaries. The sharp increases in the damping capacity of the two alloys occurs near $200^{\circ} \mathrm{C}$ (Fig. 4), coinciding with the slope changes and deviations from linearity of the elastic constants. This is further evidence that the observed changes in elastic constants and damping capacity are due to the same mechanism, namely viscous flow and sliding at the grain boundaries.

In conclusion, the elastic constants generally decrease with increasing temperature. At $200^{\circ} \mathrm{C}$, a change in the temperature dependence of the elastic constants is observed. The magnitude of this change was slightly higher for the ZK60 alloy. The internal friction in both alloys increases with increasing temperature. Below $200^{\circ} \mathrm{C}$, the internal friction of both alloys does not change significantly with temperature. Above $200^{\circ} \mathrm{C}$, the damping capacity of both alloys increases significantly with temperature. It is proposed that the observed changes in the temperature dependence of the elastic constants and the internal friction are the result of viscous flow and grain boundary sliding at elevated temperatures. The larger grains in the AZ31 alloy should produce less viscous flow and grain boundary sliding in this alloy when compared to that of the ZK60, resulting in smaller temperature dependence changes and deviations from linearity in the elastic properties at elevated temperatures. 


\section{REFERENCES}

[1] M. Radovic, E. Lara-Curzio, and L. Riester, Materials Science and Engineering A, vol. 368, 2004, pp. 56-70.

[2] A. Migliori and J.L. Sarrao, Resonant ultrasound spectroscopy: applications to physics, materials measurements and nondestructive evaluation. New York, NY: John Wiley; 1997.

[3] M.S. Blanter, H. Neuhauser, I.S. Golovin, H.R. Sinning, Internal Friction in Metallic Materials, 2007, Springer.

[4] D.W. James, Materials Science and Engineering, 4, 1, 1969, pp. 1-8.

[5] X.S. Hu, Y.K. Zhang, M.Y. Zheng, and K. Wu, Scripta Materialia, 52, 11, 2005, pp. 1141-1145.

[6] H. Watanabe, T. Mukai, M. Sugioka, and K. Ishikawa, Scripta Materialia 51 (2004) 291-295.

[7] L. Wu, A. Jain, D.W. Brown, G.M. Stoica, S.R. Agnew, B. Clausen, D.E. Fielden, and P.K. Liaw, Acta Materialia 56, 2008, pp. 688-695.

[8] L. Wu, G.M. Stoica, H.H.Liao, S.R. Agnew, E.A. Payzant, G.Wang, D.E. Fielden, L. Chen, and P.K. Liaw, Metallurgical and Materials Transactions A, 38A, 2007, pp. 2283-2289.

[9] S. K. Khanna, X. Long, W. D. Porter, H. Wang, C. K. Liu, M. Radovic and E. Lara-Curzio, Science and Technology of Welding and Joining, vol. 10, no. 1, 2005, pp. 82-87,

[10] M. Radovic, M.W. Barsoum, A. Ganguly, T. Zhen, P. Finkel, S.R. Kalidindi, and E. Lara-Curzio, Acta Materialia, 54, 2006, pp. 2757-2767.

[11] H. Chen, H. Yu, S.B. Kang, J.H. Cho, and G. Min, Materials Science and Engineering A, 527, 2010, pp. 1236-1242.

[12] M. Freels, E. Garlea, J.S. Morrell, M. Radovic, and P.K. Liaw, "HighTemperature Elastic Properties of Two Wrought Magnesium Alloys",submitted to Scripta Materialia.

[13] Frost H.J. and Ashby M.F., Deformation-mechanism maps. Oxford: Pergamon Press; 1982. p44.

[14] Wachtman Jr., J.B., Tefft, W.E., Lam Jr., D.G., and Apstein, C.S., 1961, "Exponential Temperature Dependence of Young's Modulus for Several Oxides", Physical Review, 122, 6, pp. 1754-1759.

[15] T. Ke, Physical Review, 71, 1947, pp. 533-546.

[16] F. Garofalo, Trans ASME Ser D 82, ,1960, p. 867.

[17] M.G. Zelin, H.S. Yang, R.Z. Valiev, and A.K. Mukherjee, Metallurgical Transactions A, 23A, 1992, pp. 3135-3140. 
Table 1: Nominal chemical compositions for AZ31 and ZK60 (weight percent).

\begin{tabular}{|c|c|c|c|c|c|}
\hline Material & $\boldsymbol{A l}$ & $\mathbf{Z n}$ & $\mathbf{Z r}$ & $\boldsymbol{M g}$ & Temper \\
\hline AZ31 & $3.0 \%$ & $1.0 \%$ & n/a & balance & $\mathrm{H} 24$ \\
\hline ZK60 & n/a & $6.0 \%$ & $0.5 \%$ & balance & $\mathrm{T} 5$ \\
\hline
\end{tabular}

Table 2: Linear fit of $\mathrm{E}, \mathrm{C}_{11}, \mathrm{C}_{12}$, and $\mathrm{C}_{44}$ from $25^{\circ} \mathrm{C}$ to $200^{\circ} \mathrm{C}$ for ZK60 and AZ31.

\begin{tabular}{|c|c|c|}
\hline Material & Property & Slope $\left(\mathbf{G P a} /{ }^{\circ} \mathbf{C}\right)$ \\
\hline \multirow{4}{*}{ ZK60 } & $\mathrm{E}$ & -0.0226 \\
\cline { 2 - 3 } & $\mathrm{C}_{11}$ & -0.0209 \\
\cline { 2 - 3 } & $\mathrm{C}_{12}$ & -0.0042 \\
\cline { 2 - 3 } & $\mathrm{C}_{44}$ & -0.0098 \\
\hline \multirow{4}{*}{ AZ31 } & $\mathrm{E}$ & -0.0188 \\
\cline { 2 - 3 } & $\mathrm{C}_{11}$ & -0.0198 \\
\cline { 2 - 3 } & $\mathrm{C}_{12}$ & -0.0046 \\
\cline { 2 - 3 } & $\mathrm{C}_{44}$ & -0.0078 \\
\hline
\end{tabular}

Table 3: Linear fit of $\mathrm{E}, \mathrm{C}_{11}, \mathrm{C}_{12}$, and $\mathrm{C}_{44}$ from $200^{\circ} \mathrm{C}$ to $450^{\circ} \mathrm{C}$ for ZK60 and AZ31.

\begin{tabular}{|c|c|c|}
\hline Material & Property & Slope $\left(\mathbf{G P a} /{ }^{\circ} \mathbf{C}\right)$ \\
\hline \multirow{4}{*}{ ZK60 } & $\mathrm{E}$ & -0.0297 \\
\cline { 2 - 3 } & $\mathrm{C}_{11}$ & -0.0456 \\
\cline { 2 - 3 } & $\mathrm{C}_{12}$ & -0.0177 \\
\cline { 2 - 3 } & $\mathrm{C}_{44}$ & -0.0139 \\
\hline \multirow{4}{*}{ AZ31 } & $\mathrm{E}$ & -0.0383 \\
\cline { 2 - 3 } & $\mathrm{C}_{11}$ & -0.0247 \\
\cline { 2 - 3 } & $\mathrm{C}_{12}$ & -0.0010 \\
\cline { 2 - 3 } & $\mathrm{C}_{44}$ & -0.0116 \\
\hline
\end{tabular}

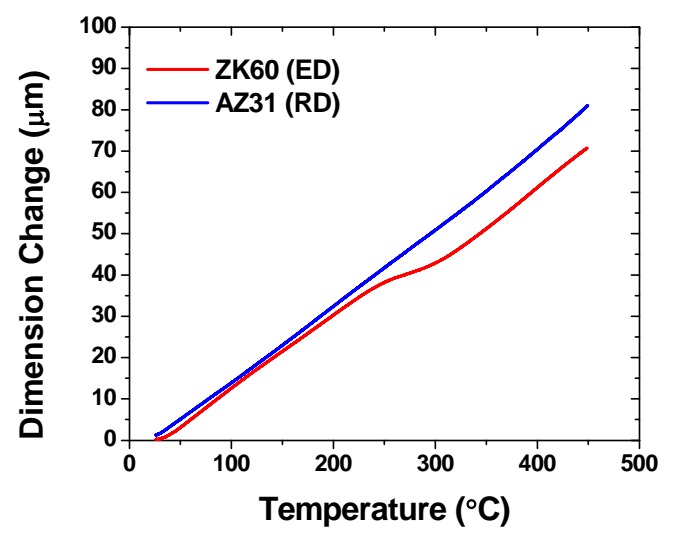

Fig. 1: Dimension change as a function of temperature for ZK60 and AZ31. 

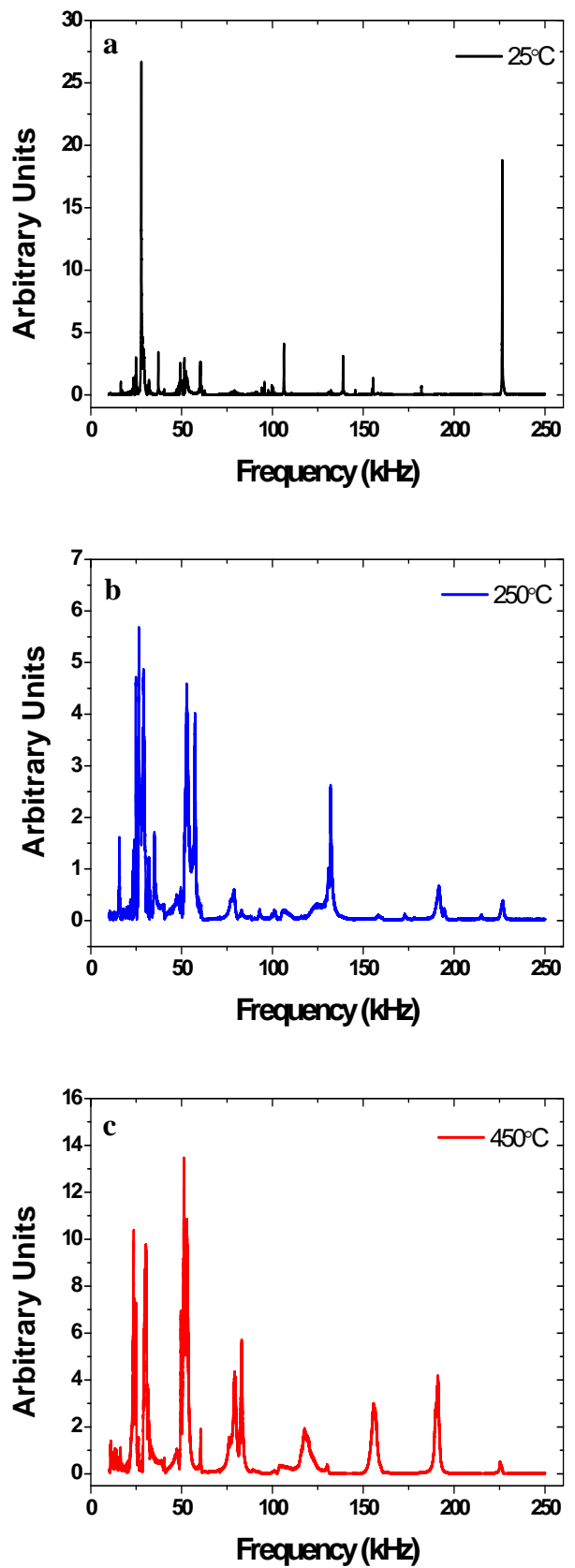

Fig. 2: Typical RUS spectra obtained for a ZK60 sample at a) $25^{\circ} \mathrm{C}$, b) $250^{\circ} \mathrm{C}$, and c) $450^{\circ} \mathrm{C}$. 

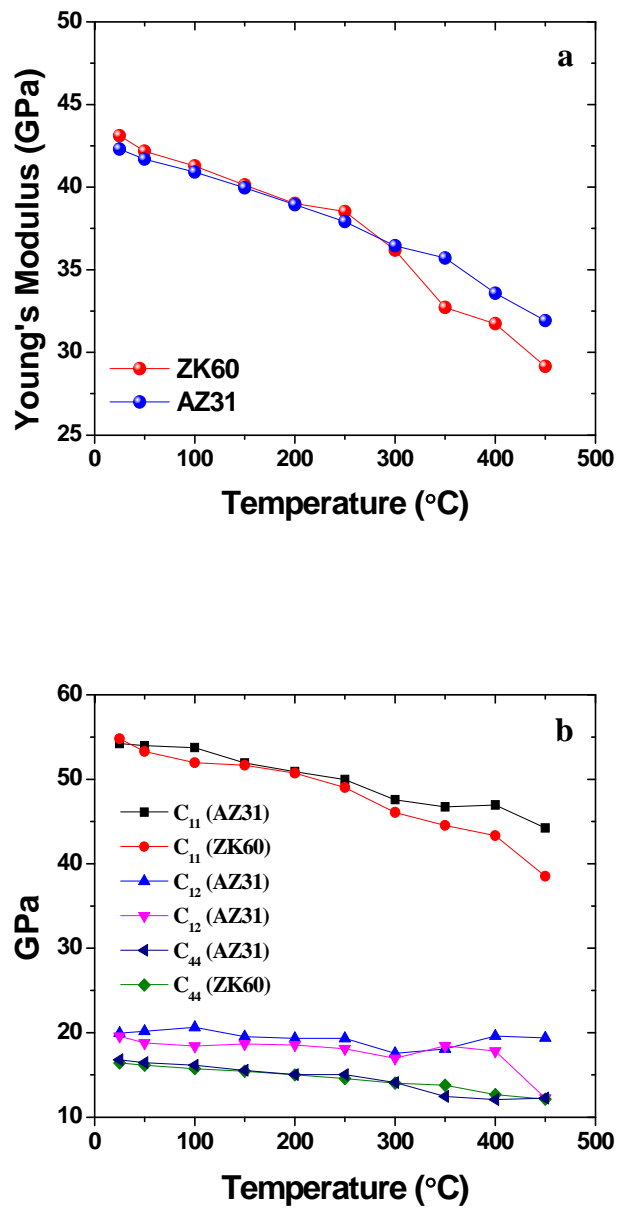

Fig. 3: Temperature dependence of (a) the Young's modulus (E), and (b) the compliances $\mathrm{C}_{11}, \mathrm{C}_{12}$, and $\mathrm{C}_{44}$, for ZK60 and AZ31.

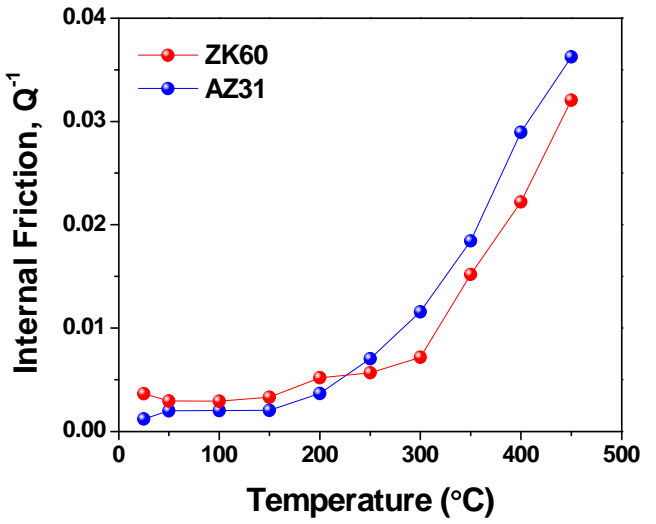

Fig. 4: Temperature dependence of internal friction in ZK60 and AZ31. 